\title{
Charpy Impact Tests of Epoxy Composites Reinforced with Giant Bamboo Fibers
}

\author{
Gabriel Oliveira Glória ${ }^{,}$,Frederico Muylaert Margem ${ }^{a}$, Carolina Gomes Dias Ribeiro ${ }^{\text {, }}$
}

\author{
Ygor Macabu de Moraes ${ }^{a}$, Renato Batista da Cruz $z^{b}$, Flavio de Andrade Silva ${ }^{c}$, Sergio Neves Monteiro ${ }^{b^{*}}$
}

\author{
${ }^{a}$ Laboratório de Materiais Avançados - LAMAV, Universidade Estadual do Norte Fluminense Darcy \\ Ribeiro - UENF, Av. Alberto Lamego, 2000, CEP 28013-602, Campos dos Goytacazes, RJ, Brazil \\ ${ }^{b}$ Departamento de Ciência dos Materiais, Instituto Militar de Engenharia - IME, Praça General \\ Tibúrcio, 80, Praia Vermelha, Urca, CEP 22290-270, Urca, Rio de Janeiro, RJ, Brazil \\ cDepartamento de Engenharia Civil, Pontificia Universidade Católica do Rio de Janeiro - PUC, \\ Rio Rua Marquês de São Vicente, 225, Gávea, CEP 22451-900, Rio de Janeiro, RJ, Brazil
}

Received: December 1, 2014; Revised: November 11, 2015

\begin{abstract}
The giant bamboo fiber is among the strongest in the Bambusa species with a potential for application as engineering material. Its properties have been evaluated but there is limited information on the impact resistance of epoxy composites incorporated with giant bamboo fibers. Therefore, this study evaluated the Charpy impact energy of epoxy matrix composites reinforced with up to $30 \mathrm{vol} \%$ of giant bamboo fibers. Specimens with Charpy configuration were press-molded with continuous and aligned giant bamboo fibers reinforcing a DGEBA-TETA epoxy as the composite matrix. The energy absorbed by the composites was obtained in standard impact tests and the fracture surface of ruptured specimens was analyzed by scanning electron microscopy, SEM. The impact energy was found to increase exponentially with the amount of incorporated fiber. SEM observations revealed the mechanism of crack propagation both in the brittle epoxy matrix and in the fiber interface of the composites.
\end{abstract}

Keywords: Charpy test, epoxy composite, giant bamboo fiber, fracture analysis

\section{Introduction}

Owing to the growing concern about the environmental degradation associated with industrial activities, our society is increasingly using biodegradable and renewable natural materials. In this view, cellulose-based natural fibers, known as lignocellulosic fibers, become a promising solution. Currently, these fibers are being considered as possible substitute for synthetic fibers, mainly the glass fiber ${ }^{1-3}$, which has since last century been used in large industrial scale but also contributing to pollution. In addition, the engineering application of lignocellulosic fibers is motivated by several advantages like low density, superior toughness and less wear of equipment used in the processing of composites ${ }^{4}$. Moreover, lignocellulosic fibers are environmentally friendly because of their characteristic of being neutral with respect to $\mathrm{CO}_{2}$ emissions, the main responsible for global warming and climate changes 5 .

The interest in engineering applications of lignocellulosic fibers as polymer composite reinforcement is translated into numerous published papers in the past decades. Review articles ${ }^{6-19}$ have contributed to disseminate and discuss investigations concerning the composites and their lignocellulosic fibers. Among them, the bamboo fiber has a potential for reinforcing polymer composites to be used in structural applications. Bamboo is a well-known grass-type plant, with a hard and stiff culm that can reach, in some species, more than $10 \mathrm{~cm}$ in cross section diameter and stand several meters height. Owing to its low density, of approximately $0.9 \mathrm{~g} / \mathrm{cm}^{3}$,

*e-mail: snevesmonteiro@gmail.com bamboo culms have been used in building construction from scaffoldings to house furniture. One of the limitations of bamboo culm for direct use in engineering systems is its cylindrical shape. Therefore, bamboo fibers stripped off from the culm have been investigated as reinforcement of polymer composite ${ }^{20-31}$. The common bamboo (Bambusa vulgaris) fiber is reported to present ${ }^{4}$ tensile strength of $106-204 \mathrm{MPa}$ and density of $1.03-1.21 \mathrm{~g} / \mathrm{cm}^{3}$. Furthermore, according to Thwe $\& \mathrm{LiaO}^{25}$, bamboo fiber-epoxy laminates can be made into specific sizes and shapes, preserving the natural microstructural properties. In fact, the use of the fibers composites can overcome constraints of the culm's cylindrical macrostructure. As a further advantage, the authors indicated that cracking and bioerosion caused by insect pests are prevented. One species of giant bamboo, Dendrocalmus giganteous, has recently attracted attention for its mechanical properties $^{32,33}$. Stripped off fiber of giant bamboo were found to present tensile strength in the range of $236-411 \mathrm{MPa}^{32}$ and elastic modulus of 5.3-21.6 $\mathrm{GPa}^{33}$. In particular, the giant bamboo fiber strength is significantly higher than that of Bambusa vulgaris ${ }^{4}$. Polymer composites reinforced with giant bamboo fibers have also been investigated for their properties $^{34-36}$, including the Izod impact resistance of polyester matrix composites ${ }^{36}$. However, a complete characterization of the impact behavior also requires Charpy impact tests of other polymeric matrices. Therefore the objective of this work was to evaluate the Charpy impact toughness of epoxy matrix composites reinforced with continuous and aligned giant bamboo fibers by means of impact tests. 


\section{Experimental Procedure}

The precursor material used in this work was the culm of giant bamboo (Dendrocalmus giganteous) kindly supplied by Prof. Khosrow Ghavami from Pontifical Catholic University of Rio de Janeiro, PUC-Rio, Brazil. Large bamboo bushes, Figure 1a, are cultivated in the Campus of PUC-Rio. Fibers were manually stripped off from dried culms, Figure 1b, with a sharp razor blade. The longitudinal direction of the fiber coincides with that of the culm and corresponds to the natural direction of the bamboo cellulose fibrils. The as-stripped bamboo fibers were dried in a laboratory stove Pro-Lab, with oven dimensions $68 \times 57 \times 53 \mathrm{~cm}^{3}$, at $60{ }^{\circ} \mathrm{C}$ for 24 hours to remove the natural moisture.

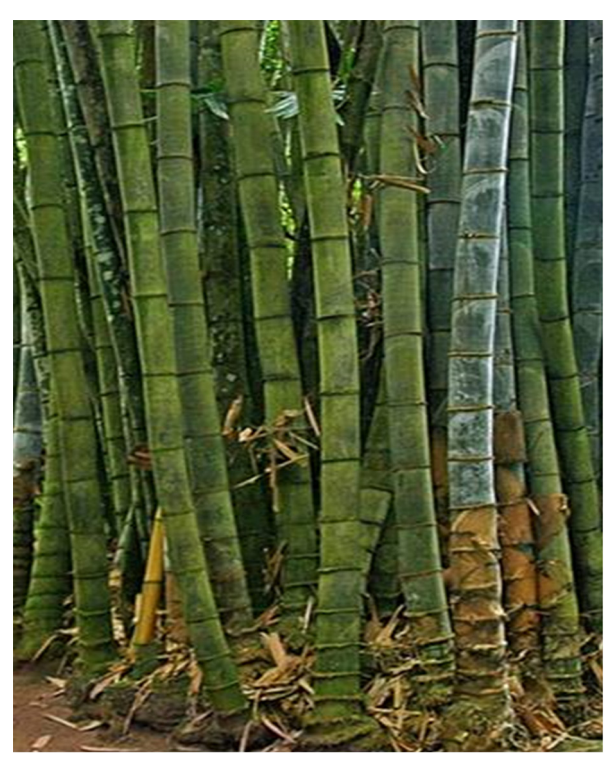

(a)

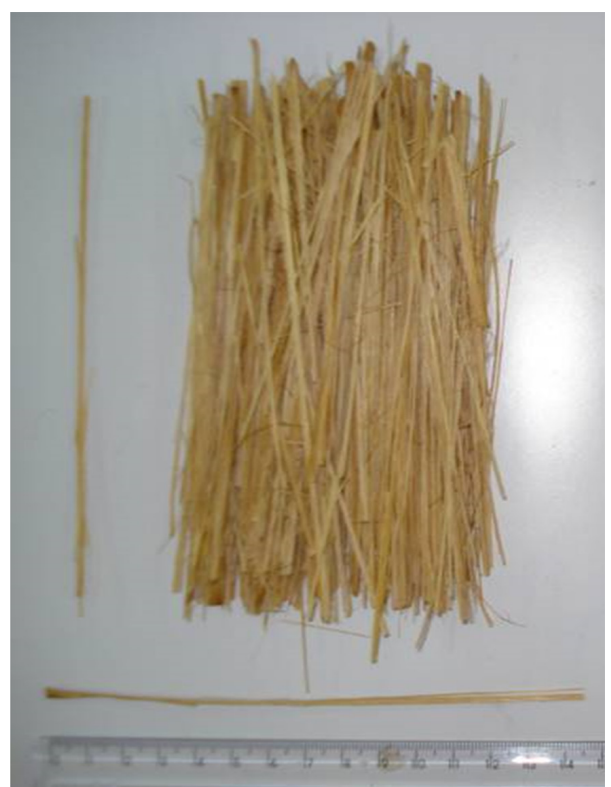

(b)

Figure 1. Bamboo trees (a) and its fibers manually stripped off from dried culms (b).
Figure 2 presents the histogram corresponding to the diameter distribution of the as-stripped giant bamboo fibers. The equivalent diameter of each fiber was actually the average value obtained by 10 different measurements performed in a profile projector at five distinct locations (two with $90^{\circ}$ rotation at each location). This histogram discloses a relatively large dispersion in the diameter $(0.1$ to $0.7 \mathrm{~mm})$, which is a consequence of the non-uniform cut procedure and physical characteristics of all lignocellulosic fiber ${ }^{4}$. It should be noticed that the giant bamboo fiber diameter range displays an average of $0.40 \mathrm{~mm}$. Based on the histogram of Figure 2, the tensile strength of the giant bamboo fibers was measured for each interval of diameter in 20 selected fibers using the Weibull statistical analysis. As aforementioned, strength values from 236 to $411 \mathrm{MPa}$ were found ${ }^{32}$ for the largest and thinnest giant bamboo fibers, respectively, with a mean proportional value of $262 \mathrm{MPa}$ for a homogeneous mixture of fibers.

Composites with up to $30 \%$ in volume of giant bamboo fibers were fabricated by placing the mixture of fibers longitudinally aligned inside a steel mold and then pouring the still fluid diglycidyl ether of the bisphenol-A (DGEBA) epoxy resin in stoichiometric proportion, $\mathrm{phr}=13$, with triethylene tetramine (TETA) hardener into the mold. A pressure of $20 \mathrm{MPa}$ was applied to the mold during the cure of the composite at room temperature (RT) for 24 hours. Standard specimens for Charpy impact test, with $125 \times 12.7 \times 10 \mathrm{~mm}^{3}$, were prepared according to the ASTM D6110-10 norm ${ }^{37}$ with giant bamboo fibers aligned along the length ${ }^{17}$.

Figure 3 illustrates (a) the Charpy impact pendulum and (b) a schematic Charpy specimen with standard ASTM dimensions. The notch, with $2.54 \mathrm{~mm}$ in depth as well as an angle of $45^{\circ}$ and a tip curvature radius of $0.25 \mathrm{~mm}$, was machined with a special milling tool. For each volume fraction of giant bamboo fiber, 10 specimens were machined to assure a statistical validation and then impact tested in the PANTEC hammer pendulum, shown in Figure $3 \mathrm{a}$.

The impact fracture surface of the specimens was gold sputtered and analyzed by scanning electron microscopy, SEM, in a model SSX-500 Shimadzu microscope with secondary electrons imaging at an accelerating voltage of $15 \mathrm{kV}$.

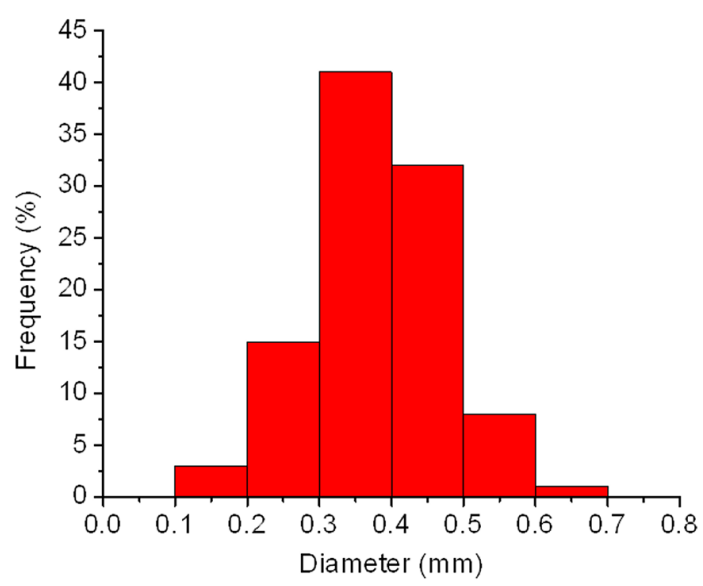

Figure 2. Histogram of the distribution of diameter of the stripped giant bamboo fibers. 


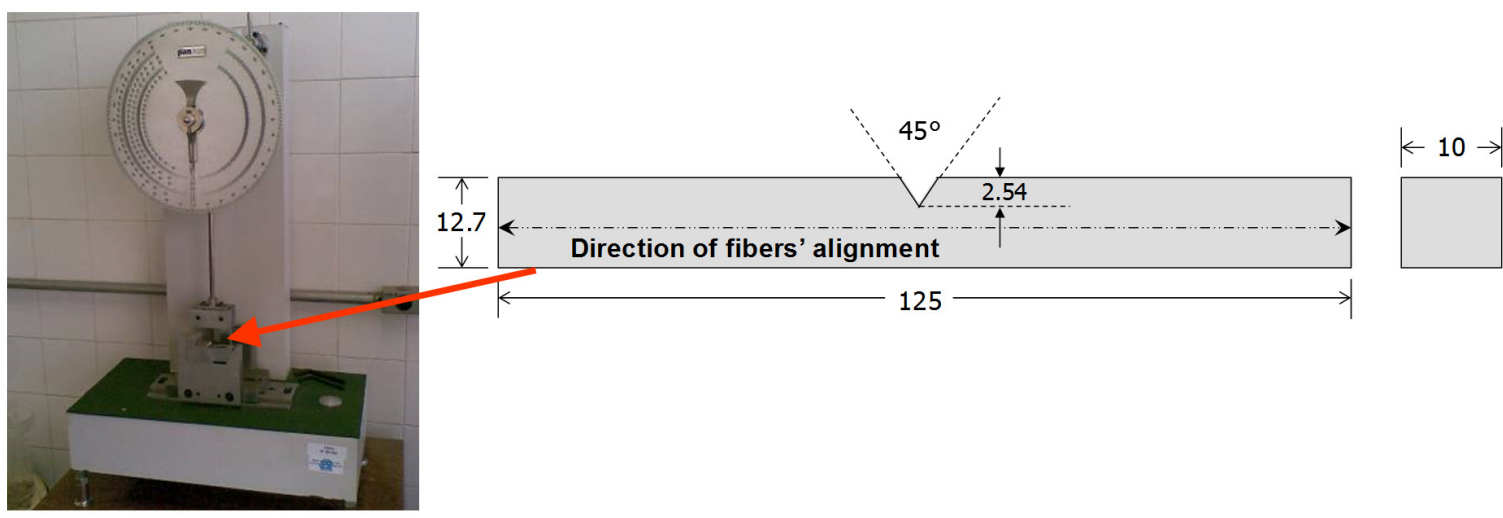

(a)

(b)

Figure 3. Charpy equipment (a) and standard specimen schematic (b) with dimensions in $\mathrm{mm}$.

\section{Results and Discussion}

Figure 4 shows the variation of the Charpy impact energy with the volume fraction of continuous and aligned giant bamboo fibers reinforcing epoxy matrix composites. In this figure, one should notice the significant increase in impact energy with incorporation of up to $30 \mathrm{vol} \%$ of giant bamboo fibers. An exponential mathematical adjustment was applied to fit the points and also to define the boundaries corresponding to the limits of standard deviation associated with the error bars. The increasing dispersion of the values in Figure 4, given by the error bars, is due to the heterogeneous characteristics of the stripped giant bamboo fibers shown in the histogram of Figure 2. Since no selection was previously conducted on the fibers used to fabricate the composites, the mixture of distinct diameters implies in dispersion on mechanical behavior. This dispersion becomes more accentuated the greater the volume fraction of fibers, as seen in Figure 4. Results of Izod impact tests in polyester matrix composites reinforced with similar continuous and aligned giant bamboo fibers ${ }^{36}$, showed comparable values as in Figure 4. However, the increase in impact energy followed a linear tendency in the case of Izod polyester composites ${ }^{36}$ rather than the exponential increase of Charpy for epoxy composites in the present work. It is worth mentioning that not only polyester and epoxy matrices have different impact properties but also Izod and Charpy tests have distinct configurations that could justify these differences.

In previous works on Charpy impact test of epoxy matrix composites reinforced with other lignocellulosic fibers ${ }^{38-45}$, an exponential increase in impact energy was also observed. Table 1 compares Charpy impact energy results of epoxy matrix composites reinforced with different lignocellulosic fibers. In this table it is observed that the giant bamboo fiber reinforced epoxy composites presents the lowest value of Charpy impact energy. Although these values in Table 1 correspond to the maximum fraction of $30 \%$, smaller fractions also follow the same trend. The reason for giant bamboo composites to have a relatively lower Charpy toughness might be due to several reasons. One important point is the fact that, different from the other fibers, the bamboo was manually extracted by cutting the hard culm

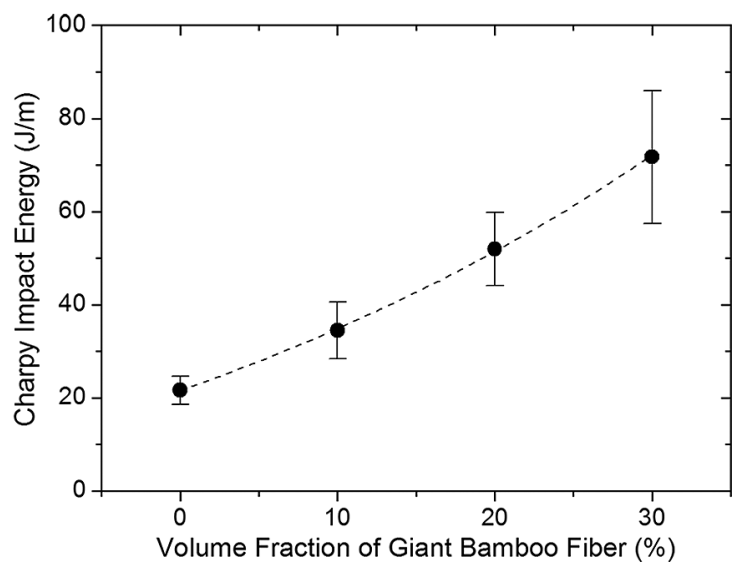

Figure 4. Charpy impact energy as a function of the amount of giant bamboo fibers.

with a razor blade. This certainly introduces comparatively more defects in the microfibrils that constitute each fiber. The other lignocellulosic fibers ${ }^{38-45}$ are extracted from the corresponding plant by softer natural processes such as retting (water immersion) and drying. In these separation processes, the fiber structure remains practically intact ${ }^{17}$. The fracture resulting from the Charpy test is another point, which might differentiate the impact toughness of the giant bamboo fiber composites from the other lignocellulosic fiber ones, as further discussed in the present work.

Table 2 indicates the exponential equations corresponding to the mathematical adjustment of the Charpy impact energy $\left(E_{i}\right)$ as a function of the volume fraction $(V)$ for each lignocellulosic fiber reinforced epoxy matrix composites presented in Table 1. As shown in Table 2, the Charpy impact energy dependence with the volume fraction of previously investigated lignocellulosic fiber epoxy composites can be adjusted to exponential equations with good statistical precision $\left(\mathrm{R}^{2}\right)$. In this table, it is worth noticing that the softly extracted fibers display higher toughness tendency, for a predicted $50 \%$ reinforcement, than the manually cut giant bamboo fiber composites. In any case, the values in Tables 1 and 2 
Table 1. Charpy impact energy of epoxy matrix composites reinforced with different lignocellulosic fibers.

\begin{tabular}{cccc}
\hline $\begin{array}{c}\text { Lignocellulosic fiber } \\
\text { reinforcing epoxy composites }\end{array}$ & $\begin{array}{c}\text { Volume Fraction } \\
(\%)\end{array}$ & $\begin{array}{c}\text { Impact Energy } \\
(\boldsymbol{J} / \boldsymbol{m})\end{array}$ & Reference \\
\hline Giant Bamboo & 30 & $72 \pm 14$ & Present work \\
Curaua & 30 & $139 \pm 38$ & 38 \\
Coir & 30 & $241 \pm 45$ & 39 \\
Piassava & 30 & $302 \pm 90$ & 40 \\
Ramie & 30 & $212 \pm 24$ & 41 \\
Jute & 30 & $197 \pm 59$ & 42 \\
Malva & 30 & $310 \pm 98$ & 43 \\
Buriti & 30 & $128 \pm 14$ & 44 \\
Sisal & 30 & $336 \pm 35$ & 45 \\
\hline
\end{tabular}

Table 2. Exponential adjustment for the variation of Charpy impact energy $\left(E_{i}\right)$ and the volume fraction of lignocellulosic fibers.

\begin{tabular}{|c|c|c|}
\hline $\begin{array}{c}\text { Lignocellulosic Fiber Reinforcing } \\
\text { Epoxy Composites }\end{array}$ & $\begin{array}{c}E_{i}(J / m) \text { and } V(\%) \\
{\left[R^{2}\right]}\end{array}$ & $\begin{array}{c}\text { Predicted Charpy Impact Energy } \\
\text { for } 50 \% \text { Fiber } \\
(\mathrm{J} / \mathrm{m})\end{array}$ \\
\hline Giant Bamboo & $E_{i}=53.69 \exp (0.022 V)-32.11\left(R^{2}=0.999\right)$ & 129 \\
\hline Curaua & $E_{i}=91.96 \exp (0.028 V)-77.60\left(R^{2}=0.992\right)$ & 295 \\
\hline Coir & $E_{i}=57.55 \exp (0.053 V)-44.30\left(R^{2}=0.999\right)$ & 238 \\
\hline Buriti & $E_{i}=99.71 \exp (0.025 V)-85.77\left(R^{2}=0.999\right)$ & 262 \\
\hline Ramie & $E_{i}=35.80 \exp (0.063 V)-22.92\left(R^{2}=0.999\right)$ & 813 \\
\hline Jute & $E_{i}=163.97 \exp (0.022 V)-120.13\left(R^{2}=0.974\right)$ & 372 \\
\hline Malva & $E_{i}=177.33 \exp (0.032 V)-150.96\left(R^{2}=0.990\right)$ & 727 \\
\hline Piassava & $E_{i}=28.18 \exp (0.080 V)-11.08\left(R^{2}=0.998\right)$ & 1527 \\
\hline Sisal & $E_{i}=41.63 \exp (0.070 V)-9.62\left(R^{2}=0.970\right)$ & 1369 \\
\hline
\end{tabular}

for continuous and aligned fibers are significantly higher than those reported for Charpy and Izod results for chopped and randomly distributed lignocellulosic fiber reinforcing other polymeric matrices ${ }^{46}$.

Figure 5 illustrates the typical macroscopic rupture aspect of Charpy specimens of epoxy composites reinforced with up to $30 \mathrm{vol} \%$ of giant bamboo fibers. In this figure, rupture is predominantly transversal to the specimen length and nucleates, as expected, at the notch. In the case of the pure epoxy $(0 \%)$ a flat fracture surface is observed, while for the composites (10, 20 and 30\%) fibers are seen sticking out of the broken surface. This indicates that the crack nucleated at the notch, upon the Charpy hammer impact, propagates across the brittle epoxy but is arrested at the fibers interface. The original crack either changes its trajectory or nucleates new longitudinal cracks in between the fiber/matrix interface. As a consequence, owing to the propagation of longitudinal cracks along the fibers interfacial length, a greater fracture area is created in association with higher impact energy ${ }^{47}$.

In Figure 5 it is also important to notice that the $30 \%$ specimen is not totally separated and few long fibers are still connecting the two parts. In fact, upon impact, the specimen bent around the hammer but did not separate in two parts due to the flexibility of some unbroken fibers. Similar situation occurred for impact tests of epoxy composites reinforced with $30 \%$ of other lignocellulosic fibers ${ }^{38-45}$. The reason for decohesion at the fiber/matrix interface, allowing longitudinal cracks to propagate and release intact giant bamboo fibers from the epoxy matrix, can be assigned to the low interfacial shear stress of any lignocellulosic fiber ${ }^{17}$.

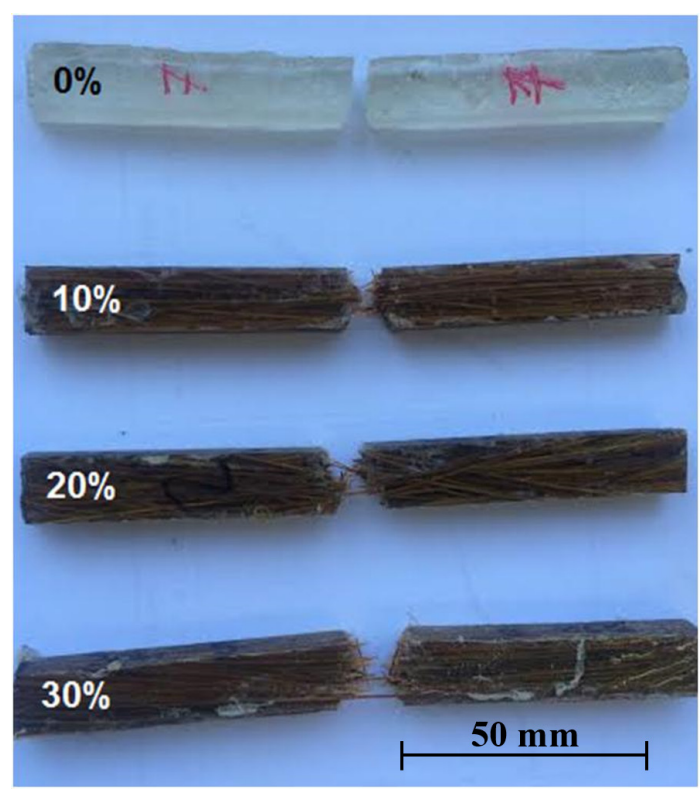

Figure 5. Typical rupture aspect of Charpy specimens of epoxy composites reinforced with different volume fractions of giant bamboo fibers.

Figure 6 shows SEM images of the impact fracture surface of a $30 \%$ giant bamboo fiber composite. With lower magnification, Figure $6 \mathrm{a}$, it can be observed several fibers attached to the epoxy matrix in a specific area. Some long 


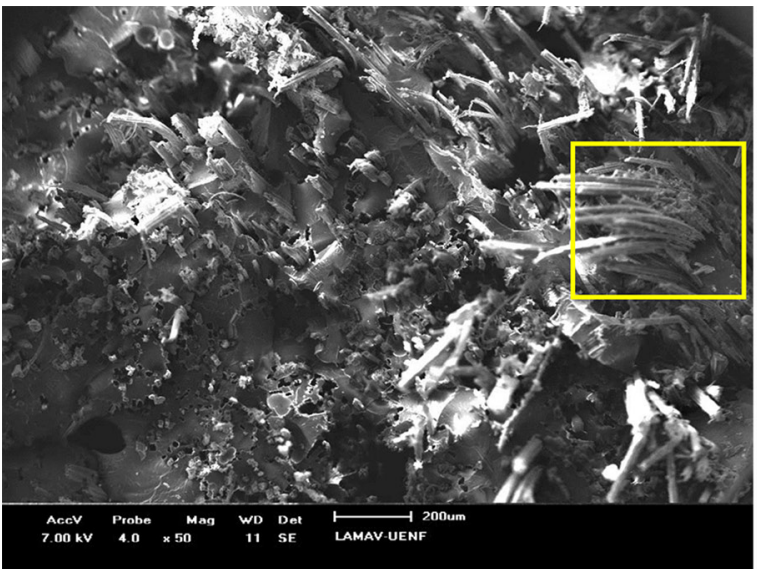

(a)

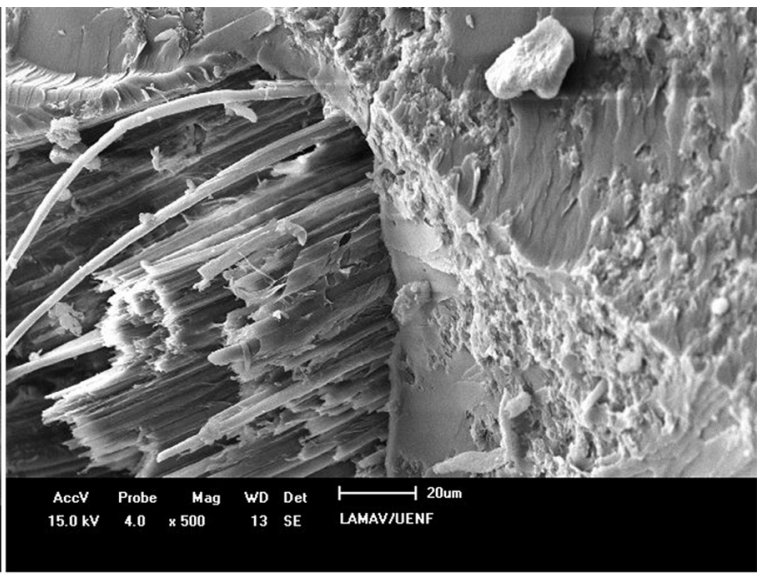

(b)

Figure 6. SEM fractographs of Charpy impact tested epoxy matrix composite reinforced with $30 \mathrm{vol} \%$ of giant bamboo fibers: (a) $50 \times$ and (b) $500 \times$ of magnification.

fibers are even sticking out of the transversal surface of the brittle epoxy matrix. A few holes could be caused by the giant bamboo fiber pullout due to, as aforementioned, longitudinal cracks that propagated at the low shear stress interface, releasing the fiber from the epoxy matrix. With higher magnification, Figure $6 \mathrm{~b}$, details of a fiber/matrix interface can be seen in a different area. The transversal rupture surface of the epoxy matrix (right side) indicates that the original crack nucleated at the specimen notch, was arrested at the fiber. The several microfibrils that constitute the fiber (left side) were longitudinally separated from the matrix by interface propagating cracks. A similar fiber/matrix interface is shown inside the insert in Figure 6a. Finally, the microfibrils were broken by tensile stresses generated upon the impact. These fiber/matrix interface longitudinal fracture and microfibrils tensile rupture provide the major contribution to the Charpy impact energy and justify its exponential increase, Figure 4 and Table 2, with the volume fraction of giant bamboo fibers.

\section{Conclusions}

- Epoxy matrix composites reinforced with up to $30 \%$ of continuous and aligned giant bamboo fibers display an exponential increase in toughness, measured by Charpy impact tests, as a function of the fibers volume fraction.

\section{References}

1. Corbière-Nicollier T, Laban BG, Lundquist L, Leterrier Y, Manson JAE and Jolliet O. Life cycle assessment of biofibres replacing glass fibres as reinforcement in plastics. Resources, Conservation and Recycling. 2001; 33(4):267-287. http://dx.doi. org/10.1016/S0921-3449(01)00089-1.

2. Wambua P, Ivens I and Verpoest I. Natural fibers: can they replace glass and fibre reinforced plastics? Composites Science and Technology. 2003; 63(1):1259-1264. http://dx.doi.org/10.1016/ S0266-3538(03)00096-4.

3. Joshi SV, Drzal LT, Mohanty AK and Arora S. Are natural fiber composites environmentally superior to glass fiber reinforced
- This increase in Charpy toughness is relatively smaller than those reported for other lignocellulosic fibers epoxy composites, probably due to defects introduced in the giant bamboo fiber during extraction by manual cut of the hard culm with razor blade.

- The exponential increase can be attributed to decohesion of the fiber/matrix low shear stress interface and tensile rupture of the microfibrils. These mechanisms result in higher absorbed energy as a consequence of longitudinal propagation of cracks and multiple broken areas of the numerous microfibrils.

- In spite of mechanisms responsible for the transversal fracture in the epoxy matrix as well as longitudinal decohesion of the fiber/matrix interface and tensile rupture of microfibrils, some giant bamboo fibers remained intact after the impact. In the $30 \mathrm{vol} \%$ fiber epoxy composites these intact fibers, owing to their bend flexibility, avoid total separation of the specimen in two parts.

\section{Acknowledgements}

The authors thank the support to this investigation by the Brazilian agencies: CNPq, CAPES, FAPERJ and TECNORTE/FENORTE.

composites? Compos Part A. 2004; 35(3):371-376. http://dx.doi. org/10.1016/j.compositesa.2003.09.016.

4. Monteiro SN, Lopes FPD, Barbosa AP, Bevitori AB, Silva ILA and Costa LL. Natural lignocellulosic fibers as engineering materials: an overview. Metallurgical and Materials Transactions A, Physical Metallurgy and Materials Science. 2011; 42(10):29632974. http://dx.doi.org/10.1007/s11661-011-0789-6.

5. Gore A. An inconvenient truth. the planetary emergency of global warming and what we can do about it. Emmaus: Rodale Press; 2006.

6. Satyanarayana KG, Sukumaran K, Mukherjee PS, Pavithran $\mathrm{C}$ and Pillai SG. Natural fibre-polymer composites. Cement 
and Concrete Composites. 1990; 12(2):117-136. http://dx.doi. org/10.1016/0958-9465(90)90049-4.

7. Bledzki AK and Gassan J. Composites reinforced with cellulosebased fibers. Progress in Polymer Science. 1999; 4(1):221-274. http://dx.doi.org/10.1016/S0079-6700(98)00018-5.

8. Saheb D and Jog JP. Natural fiber polymer composites: a review. Advances in Polymer Technology. 1999; 18(1):351-363. http:// dx.doi.org/10.1002/(SICI)1098-2329(199924)18:4<351::AIDADV6>3.0.CO;2-X.

9. Mohanty AK, Misra M and Hinrichsen G. Biofibers, biodegradable polymers and biocomposites: an overview. Macromolecular Materials and Engineering. 2000; 276(1):1-24. http://dx.doi. org/10.1002/(SICI)1439-2054(20000301)276:1<1::AIDMAME1>3.0.CO;2-W.

10. Eichhorn SJ, Baillie CA, Zafeiropoulos N, Mwaikambo LY, Ansell MP and Dufresne A. Review: current international research into cellulosic fibres and composites. Journal of Materials Science. 2001; 36(9):2107-2131. http://dx.doi. org/10.1023/A:1017512029696.

11. Mohanty AK, Misra M and Drzal LT. Sustainable bio-composites from renewable resources: opportunities and challenges in the green materials world. Journal of Polymers and the Environment. 2002; 10(1/2):19-26. http://dx.doi.org/10.1023/A:1021013921916.

12. Netravali $\mathrm{AN}$ and Chabba S. Composites get greener. Materials Today. 2003; 6(4):22-29. http://dx.doi.org/10.1016/S13697021(03)00427-9.

13. Crocker J. Natural materials innovative natural composites. Materials Technology. 2008; 2-3(3):174-178. http://dx.doi. org $/ 10.1179 / 175355508 X 373378$.

14. John MJ and Thomas S. Biofibers and biocomposites. Carbohydrate Polymers. 2008; 71(3):343-364. http://dx.doi. org/10.1016/j.carbpol.2007.05.040.

15. Satyanarayana KG, Arizaga GGC and Wypych F. Biodegradable composites based on lignocellulosic fibers: an overview. Progress in Polymer Science. 2009; 34(9):982-1021. http:// dx.doi.org/10.1016/j.progpolymsci.2008.12.002.

16. Monteiro SN, Lopes FPD, Ferreira AS and Nascimento DCO. Natural fiber polymer matrix composites: cheaper, tougher and environmentally friendly. JOM. 2009; 61(1):17-22. http:// dx.doi.org/10.1007/s11837-009-0004-z.

17. Kalia S, Kaith BS and Kaur I, editors. Bio-and nano-polymer composites. Berlin: Springer-Verlag; 2011.. http://dx.doi. org/10.1007/978-3-642-17370-7.

18. Faruk O, Bledzki AK, Fink HP and Sain M. Biocomposites reinforced with natural fibers. Progress in Polymer Science. 2012; 37(11):1555-1596. http://dx.doi.org/10.1016/j. progpolymsci.2012.04.003.

19. Thakur VK, Thakur MK and Gupta RK. Review: raw natural fibers based polymer composites. International Journal of Polymer Analysis and Characterization. 2014; 19(3):256-271. http://dx.doi.org/10.1080/1023666X.2014.880016.

20. Shin FG, Xian XJ, Zheng WP and Yipp MW. Analysis of the mechanical properties and microstructure of bamboo epoxy composites. Journal of Materials Science. 1989; 24(10):34833490. http://dx.doi.org/10.1007/BF02385729.

21. Jain S, Kumar R and Jindal UC. Mechanical behavior of bamboo and bamboo composites. Journal of Materials Science. 1992; 27(17):4598-4604. http://dx.doi.org/10.1007/BF01165993.

22. Jain S, Kumar R and Jindal UC. Development and fracture mechanism of the bamboo/polyester resin composite. Journal of Materials Science Letters. 1993; 12:558-560.

23. Jain S and Kumar R. Processing of bamboo fiber reinforced plastics composites. Materials and Manufacturing Processes. 1994; 9(5):813-828. http://dx.doi.org/10.1080/10426919408934955.
24. Chen X, Guo Q and Mi Y. Bamboo fiber reinforced polypropylene composites: a study of the mechanical properties. Journal of Applied Polymer Science. 1998; 69(10):1891-1899. http://dx.doi. org/10.1002/(SICI)1097-4628(19980906)69:10<1891::AIDAPP1>3.0.CO;2-9.

25. Thwe MM and Liao K. Effects of environmental aging on the mechanical properties of bamboo glass fiber reinforced polymer matrix hybrid composites. Composites Part A, Applied Science and Manufacturing. 2002; 33(1):43-52. http://dx.doi. org/10.1016/S1359-835X(01)00071-9.

26. Okubo K, Fujii T and Yamamoto Y. Development of bamboo based polymer composites and their mechanical properties. Composites Part A, Applied Science and Manufacturing. 2004; 35(3):377383. http://dx.doi.org/10.1016/j.compositesa.2003.09.017.

27. Okubo K, Fujii T and Yamashita N. Improvement of interfacial adhesion in bamboo polymer composite enhanced with microfibrillated cellulose. International Journal Series A Solid Mechanics and Material Engineering. 2005; 48(4):199-204. http://dx.doi.org/10.1299/jsmea.48.199.

28. Lee SH and Wang S. Biodegradable polymer/bamboo fiber biocomposite with bio-based coupling agent. Composites Part A, Applied Science and Manufacturing. 2006; 37(1):80-91. http://dx.doi.org/10.1016/j.compositesa.2005.04.015.

29. Shibata S, CaoY and Fukumoto I. Flexural modulus of the unidirectional and random composites made from biodegradable resin and bamboo and kenaf fibres. Composites Part A, Applied Science and Manufacturing. 2008; 39(4):640-646. http://dx.doi. org/10.1016/j.compositesa.2007.10.021.

30. Huang $X$ and Netravali A. Biodegradable green composites made using bamboo micro/nano-fibrils and chemically modified soy protein resin. Composites Science and Technology. 2009; 69(78):1009-1015. http://dx.doi.org/10.1016/j.compscitech.2009.01.014.

31. Costa LL, Monteiro SN and Loiola RL. Mechanical behavior of polyester composites reinforced with continuous bamboo fibers. In: Proceedings of the Characterization of Minerals, Metals \& Materials - TMS Conference; 2010; Seattle, USA. Warrendale: The Minerals, Metals \& Materials Society; 2010. p. 1-6.

32. Martins LBS, Rosa NCG, Margem FM and Monteiro SN. Weibull analysis of tensile strength behavior of giant bamboo fibers of the species Dendrocalmus giganteous. In: Proceedings of the Characterization of Minerals, Metals \& Materials - TMS Conference; 2012; Orlando, USA. Hoboken: John Wiley \& Sons; 2012. p. 1-9.

33. Martins LBS, Monteiro SN, Margem FM, Loiola RL, Pereira AC and Margem JI. Weibull analysis of the elastic modulus of bamboo fibers of the species Dendrocalmus giganteous. In: Hwang JY, Bai C, Carpenter JS, Ikhmayies S, Li B, Monteiro SN, et al., editors. Characterization of Minerals, Metals \& Materials 2013. Hoboken: John Wiley \& Sons; 2013. p. 441448. http://dx.doi.org/10.1002/9781118659045.ch51.

34. Monteiro SN, Margem FM, Martins LBS, Loiola RL and Oliveira MP. Dynamic mechanical analysis of polyester composites reinforced with giant bamboo (Dendrocalmus giganteous) fiber. Materials Science Forum. 2014; 775-776:302-307. http:// dx.doi.org/10.4028/www.scientific.net/MSF.775-776.302.

35. Monteiro SN, Margem FM, Martins LBS, Loiola RL and Oliveira MP. Tensile Strength of Polyester Matrix Composites Reinforced with Giant Bamboo (Dendrocalmus Giganteus) Fibers. Materials Science Forum. 2014; 775-776:308-313. http://dx.doi.org/10.4028/www.scientific.net/MSF.775-776.308.

36. Martins LBS, Margem FM, Monteiro SN, Loiola RL and Margem JI. Izod impact test of polyester composites reinforced with bamboo fibers of the species Dendrocalmus giganteous. In: 
Carpenter JS, Bai C, Hwang JY, Ikhmayies S, Li B, Monteiro SN, et al., editors. Characterization of Minerals, Metals \& Materials 2014. Hoboken: John Wiley \& Sons; 2013. p. 581587.

37. American Society for Testing and Materials - ASTM. ASTM D6110-10: standard test method for determining the charpy impact resistance of notched specimens of plastics. West Conshohocken: ASTM International; 2010.

38. Ferreira AS, Monteiro SN, Lopes FPD and Aquino RCMP. Analysis of the impact resistance of epoxy composites reinforced with aligned curaua fibers. In: Proceedings of the 63th Annual Congress of the Brazilian Association of Metallurgy, Materials and Mining; 2008; Santos, Brazil. São Paulo: Brazilian Association of Metallurgy, Materials and Mining; 2008. p. 1-9. In Portuguese.

39. Costa LL, Santafé HPG Jr and Monteiro SN. Charpy impact toughness of epoxy composites reinforced with coir fibers. In: Proceedings of the Brazilian Congress on Materials Science and Engineering, CBECIMat; 2008; Porto de Galinhas, Brazil. São Paulo: Metallum; 2008. p. 1-12. In Portuguese.

40. Monteiro SN, Oliveira DC and Motta LC. Charpy impact toughness of piassava fibers reinforced epoxy matrix composites. In: Proceedings of the Brazilian Congress on Materials Science and Engineering, CBECIMat; 2008; Porto de Galinhas, Brazil. São Paulo: Metallum; 2008. p. 1-11. In Portuguese.

41. Monteiro SN, Margem FM and Santos LFL Jr. Charpy impact energy of epoxy matrix composites reinforced with ramie fibers. In: Proceedings of the 64th Annual Congress of the Brazilian Association of Metallurgy, Materials and Mining; 2009; Belo Horizonte, Brazil. São Paulo: Brazilian Association of Metallurgy, Materials and Mining; 2009. p. 1-9. In Portuguese.
42. Bevitori AB, Silva ILA, Oliveira CG, Margem FM and Monteiro $\mathrm{SN}$. Charpy toughness behavior of continuous and aligned jute fibers reinforced epoxy matrix composites. In: Proceedings of the 68th Annual Congress of the Brazilian Association of Metallurgy, Materials and Mining; 2013; Belo Horizonte, Brazil. São Paulo: Brazilian Association of Metallurgy, Materials and Mining; 2013. p. 1-7. In Portuguese.

43. Margem JI. Study of the Structural Characteristics and Properties of Polymer Composites Reinforced with Malva Fibers. [Dissertation]. Campos dos Goytacazes: Universidade Estadual do Norte Fluminense Darcy Ribeiro; 2013.

44. Barbosa AP, Oliveira MP, Altoé GR, Margem FM and Monteiro SN. Charpy impact tests in epoxy matrix composites reinforced with buriti fibers. Materials Science Forum. 2014; 775-776:296301. http://dx.doi.org/10.4028/www.scientific.net/MSF.775776.296 .

45. Monteiro SN, Margem FM, Pereira AC, Simonassi NT and Oliveira MP. Charpy impact tests in epoxy matrix composites reinforced with continuous sisal fibers. Materials Science Forum. 2014; 775-776:290-295. http://dx.doi.org/10.4028/ www.scientific.net/MSF.775-776.290.

46. Leão AL, Tan IH and Caraschi JC. Curaua fiber: a tropical natural fibre from Amazon: potential and applications in composites. In: Proceedings of the International Conference on Advanced Composites; 1998; Hurghada, Egipt. Cairo: Ain Shams University; 1998. p. 557-564.

47. Fu SY, Lauke B, Mäder E, Hu X and Yue CY. Fracture resistance of short-glass-fiber-reinforced and short-carbon-fiber-reinforced polypropylene under Charpy impact load and dependence on processing. Journal of Materials Processing Technology. 1999; 89:501-507. http://dx.doi.org/10.1016/S0924-0136(99)00065-5. 